\title{
(Re) Contextos da Prática como Componente Curricular: formação inicial de professores de Ciências e Biologia
}

\section{(Changing) Contexts of Practice as a Curricular Component: the initial training of Science and Biology teachers}

Liciane Mateus da Silva ${ }^{1}$

Lúcia de Fátima Dinelli Estevinho²

'Instituto Federal de Educação, Ciência e Tecnologia do Triângulo Mineiro (IFMT), Pró-Reitoria de Extensão e Cultura, Uberaba, MG, Brasil. Autora correspondente: liciane@iftm.edu.br

${ }^{2}$ Universidade Federal de Uberlândia (UFU), Instituto de Biologia, Programa de Pós-Graduação em Educação, Uberlândia, MG, Brasil.

Resumo: Este artigo é um recorte de uma pesquisa que buscou analisar modos de funcionamento da Prática como Componente Curricular (PCC) de cursos de Licenciatura em Ciências Biológicas de Institutos Federais de Educação, Ciência e Tecnologia, focalizando, especificamente, o curso de um instituto federal do estado de Minas Gerais. Para o estudo, foi utilizada pesquisa de abordagem qualitativa que empregou diferentes metodologias e técnicas para coletas de dados como: acompanhamento de aulas, encontros para discussões, elaboração e divulgação de material didático, análise de Projeto Pedagógico, planos de ensino, propostas e relatórios acerca da PCC e currículos dos formadores. Os conceitos de recontextualização e discurso pedagógico de Basil Bernstein configuram-se importantes aportes teóricos para a discussão dos dados, estudados pela Análise de Conteúdo, e que evidenciam um destaque ao sentido de instrumentalização técnica conferida à PCC, cuja organicidade ratifica a dicotomia teoria-prática, não privilegia a abordagem interdisciplinar, e cria hierarquias entre as formas de conhecimento.

Palavras-chave: Ensino de biologia; Formação inicial do professor; Escola técnica superior; Racionalidade técnica; Prática pedagógica.

Abstract: This paper is an excerpt from a study that sought to analyze modes of operation of the Practice as a Curricular Component (PCC) of the Licensure Programs in Biological Sciences in the Federal Institutes of Education, Science and Technology, focusing on the program at the Federal Institute of the state of Minas Gerais, Brazil. For the study, a qualitative approach to research was taken, which applied different methodologies and techniques for data collection such as: follow-up to classes; meetings for discussions, preparation, and dissemination of teaching material; analysis of the Pedagogical Project, teaching plans, proposals and reports about the PCC and the curricula of the trainers. Basil Bernstein's concepts of recontextualization and pedagogical discourse are an important theoretical contribution to the discussion of data, which were subjected to Content Analysis, and highlighted the sense of technical instrumentalization, given to the PCC, whose organicity ratifies the theory-practice dichotomy, does not privilege the interdisciplinary approach, and creates hierarchies between the forms of knowledge.

Keywords: Biology teaching; Initial teacher training; Higher technical school; Technical rationality; Pedagogical practice.

Recebido em: 12/04/2020

Aprovado em: 07/12/2020 


\section{Prática com o Componente Curricular nas Licenciaturas: do discurso pedagógico oficial ao contexto de reprodução ${ }^{1}$}

O termo Prática como Componente Curricular (PCC) passou a ser referenciado nos documentos oficiais do Conselho Nacional de Educação (CNE) acerca da formação de professores do país a partir de 2001. A redação desses documentos prima, de modo geral, pela indissociabilidade teoria-prática, por uma práxis integradora que estreite o liame universidade-escola-sociedade e pela formação da identidade de um docente reflexivo e atuante na sociedade. Nesse sentido, a PCC, que deve permear todo o curso de licenciatura, com no mínimo 400 horas, deve contribuir, assim como as demais dimensões do currículo, com uma formação voltada à reflexão e mediante o trabalho de atividades que trazem à tona experiências efetivamente formativas. As orientações dos documentos do CNE evidenciam a necessidade de reestruturação dos currículos acerca da organização das unidades curriculares e da carga horária; todavia, nos processos de reformulações dos cursos de formação de professores, ainda permanecem várias discussões, incompreensões e interpretações com relação à estruturação da PCC (BARBOSA, 2015; KASSEBOEHMER; FARIAS, 2012; LIMA NETO, 2018; MOHR; WIELEWICKI, 2017; OLIVEIRA NETO, 2016; REAL, 2012; TERRERI; FERREIRA, 2013; ZABEL; MALHEIROS, 2018). Segundo Schneider (2007, p. 6), o caráter mutifacetado das Diretrizes Nacionais Curriculares para Formação de Professores (DCN) contribuiu para que haja recontextualizações desses textos, "[...] evidenciando continuidades e rupturas acerca da constituição da profissionalidade do professor da educação básica". Para Terreri e Ferreira (2013, p. 1002, grifos das autoras), esses documentos legais são "[...] textos produtores e recontextualizadores de políticas de currículo que conversam, apoiando e, simultaneamente, subvertendo aquilo que vem dos contextos macro e micro". Com relação à implementação da PCC nos cursos de formação de professores, nas palavras de Brito (2011, p. 121), que investigou as configurações curriculares dos cursos de Licenciatura em Ciências Biológicas das Universidades Estaduais da Bahia para inserir as 400 horas de PCC, "[...] entendo que a prática enquanto dimensão formativa amplia-se no contexto dos cursos [...], via recontextualização de políticas curriculares nacionais para formação de professores (DCN)".

Nessa perspectiva, os conceitos de recontextualização e discurso pedagógico, elaborados por Basil Bernstein, contribuem para o entendimento da estruturação da PCC, desde sua preconização nos textos oficiais até seu desenvolvimento no âmbito dos cursos de licenciatura. Bernstein foi um sociólogo britânico que trouxe contribuições para o campo educacional, cujas ideias têm sido utilizadas para se compreender os diversos sistemas educativos contemporâneos e suas transformações (DAVIES, 2001). Segundo Morais e Neves (2001, 2009), a teoria de Bernstein pode ser utilizada tanto na dimensão conceitual quanto metodológica. Ainda que não tenha discutido especificamente o ensino de Ciências e a formação de professores, há trabalhos de pesquisadores do Grupo de Estudos Sociológicos da Sala de Aula (ESSA), interligado ao Instituto de Educação da Universidade de Lisboa, que desenvolveram

'Este artigo é um recorte de uma tese de doutorado (SILVA, 2019), cujo tema foi a Prática como Componente Curricular (PCC) de um curso de Licenciatura em Ciências Biológicas de um Instituto Federal do Estado de Minas Gerais. 
estudos empíricos fundamentados na teoria sociológica de Bernstein tanto na área de Ciências quanto em outras áreas do currículo.

Segundo Bernstein (1996), quando um texto se desloca de seu contexto de produção, sendo apropriado por diferentes agentes recontextualizadores, ele sofre transformações, reguladas por um princípio de descontextualização, é deslocado, antes de ser relocado, contribuindo para que não seja mais o mesmo texto. Nessa perspectiva, são as regras recontextualizadoras que regulam, segundo o autor, a constituição do discurso pedagógico específico. Para Bernstein (1996, p. 243), o termo texto "[...] pode designar o currículo dominante, a prática pedagógica dominante, mas também qualquer representação pedagógica falada, escrita, visual, espacial ou expressa na postura ou na vestimenta".

O discurso pedagógico é definido, por Bernstein (1996, p. 259), como "[...] um princípio que tira (desloca) um discurso de sua prática e contexto substantivos e reloca aquele discurso de acordo com seu próprio princípio de focalização e reordenamento seletivos". O modelo do Discurso Pedagógico de Bernstein inclui três níveis fundamentais de análise: geração, recontextualização e transmissão. Os dois primeiros níveis estão relacionados à produção e o terceiro com a reprodução do discurso pedagógico (MORAIS; NEVES, 2007).

No nível da geração do discurso pedagógico, há uma interação entre os campos internacional, econômico, do Estado, e do controle simbólico, resultando nos princípios dominantes da sociedade - Discurso Regulador Geral (DRG) (normas, valores, atitudes). Esse discurso, institucionalizado por meio de documentos legais e administrativos, corresponde ao discurso oficial do Estado. Ao integrarem o DRG, os princípios dominantes da sociedade estão sujeitos ao Campo de Recontextualização Oficial (CRO) (Ministério da Educação e suas respectivas secretarias), sofrendo uma primeira recontextualização. Esse processo de adaptação dos princípios dominantes a um novo contexto é responsável pela produção do Discurso Pedagógico Oficial (DPO) (currículo escolar, programas e normas diversas). Esse discurso produzido entra no Campo da Recontextualização Pedagógica (CRP) (departamentos universitários de educação, instituições formadoras de professores, mídia especializada), experimentando um segundo processo de recontextualização. Emana-se desse processo o Discurso Pedagógico de Reprodução (DPR), que, ao ser introduzido nos contextos de reprodução pedagógica (diferentes níveis de ensino), pode ser subordinado a princípios de recontextualização mediante o contexto específico de uma escola e, principalmente, de acordo com a prática pedagógica do professor que é influenciada por diferentes fatores (SILVA; MORAIS; NEVES, 2013).

Esse modelo corrobora para o entendimento da estruturação da PCC nos cursos de licenciatura, uma vez que essa dimensão formativa, presente nas DCNs, é um Discurso Pedagógico Oficial (DPO) que sofre um processo de recontextualização no Campo da Recontextualização Pedagógica (CRP). O PPC e os planos de ensino dos cursos de licenciatura da instituição formadora representam o Discurso Pedagógico de Reprodução (DPR) que emerge no Campo de Recontextualização Pedagógica (CRP). As práticas pedagógicas dos professores formadores e dos licenciandos, presentes no Contexto de Reprodução, representam o Discurso Pedagógico de Reprodução (DPR), que sofre influência tanto dos textos oficiais (DPO) quanto dos documentos elaborados pela instituição formadora como os PPCs e planos de ensino das disciplinas. No que concerne à PCC, ela é constantemente recontextualizada conforme o discurso, os 
objetivos e as metodologias de formação da instituição. Destarte, a prática pedagógica dos futuros docentes é submetida a diversas circunstâncias durante a formação inicial que influenciarão em seu discurso pedagógico na educação básica. Nessa perspectiva, este estudo visou analisar modos de funcionamento da Prática como Componente Curricular (PCC), enquanto dimensão formativa e discurso pedagógico, do curso de Licenciatura em Ciências Biológicas do Instituto Federal do Triângulo Mineiro (IFTM) e suas contribuições na formação docente.

\section{O Lócus de Pesquisa e Percursos Investigativos}

A Lei n. ${ }^{\circ} 11.892$, de 29 de dezembro de 2008 dispõe sobre a criação dos Institutos Federais de Educação, Ciência e Tecnologia (IF) no país, cujo objetivo é oferecer o ensino médio integrado a cursos técnicos, ensino tecnológico, de graduação e de pósgraduação. Essas instituições são também responsáveis pela formação de professores, garantindo o mínimo de $20 \%$ (vinte por cento) de suas vagas para oferta de cursos de licenciatura e programas especiais de formação pedagógica de professores para a educação básica, especialmente nas áreas de ciências e matemática, e para a educação profissional (BRASIL, 2008).

O IFTM tem, atualmente, além da Reitoria em Uberaba, estado de Minas Gerais, nove campi: Avançado Campina Verde, Avançado Uberaba Parque Tecnológico, Ituiutaba, Paracatu, Patos de Minas, Patrocínio, Uberaba, Uberlândia e Uberlândia Centro. O curso de Licenciatura em Ciências Biológicas do IFTM foi criado em 2010, ofertado no campus Uberaba, na modalidade presencial e no período noturno ${ }^{2}$. Desde a sua criação foram publicados quatro PPC nos anos de 2010, 2013, 2015 e 2017. O curso foi avaliado pela primeira vez pelo Ministério da Educação (MEC) em 2014, obtendo nota 4, tendo como referência o PPC de 2013. O relatório da comissão avaliadora do MEC ponderou, acerca das Práticas Pedagógicas Componentes Curriculares (PPCC) ${ }^{3}$, que sua realização "[...] em todas as unidades curriculares é um fato relevante e elogiável, constituindo-se em um diferencial para a efetiva formação de Professores de Ciências Biológicas pelo uso avaliado" (INSTITUTO FEDERAL DO TRIÂNGULO MINEIRO, 2014, p. 14, grifos nossos). A carga horária total dessa dimensão formativa correspondia ao somatório da carga horária da disciplina de Prática Pedagógica, distribuída ao longo dos oito períodos do curso (216 horas), e inserida em 19 unidades curriculares elegidas na matriz curricular (190 horas). A unidade curricular Prática Pedagógica previa a reflexão teórica e a produção de objetos educacionais ${ }^{4}$ articulada em conexão com as demais unidades curriculares do período que tinham carga horária de PPCC na forma de Projetos Integrados. Segundo o PPC,

\footnotetext{
${ }^{2} \mathrm{~A}$ partir do primeiro semestre do ano de 2016, o curso passou a ser integral para as turmas ingressantes.

${ }^{3}$ Esta é a terminologia utilizada no PPC de Licenciatura em Ciências Biológicas do IFTM para se referir à Prática como Componente Curricular (PCC) constante na legislação que a define e ampara.

${ }^{4}$ Essa terminologia restringe os recursos didáticos a recursos midiáticos, por isso, durante este texto, utiliza-se a terminologia materiais didáticos, uma vez que os licenciandos elaboravam objetos em diversos suportes e nas mais diversas naturezas como maquetes, banners, cartazes, modelos, vídeos, apresentações em Power Point, apostilas, dentre outros, não ficando restritos às mídias digitais.
} 
[...]. Os temas escolhidos desencadearão o estudo de conteúdos integradores em diferentes áreas do saber e serão trabalhados de forma dialógica integrando teoria e prática, privilegiando a formação interdisciplinar. Os conteúdos deverão ser tratados como meio e suporte para a constituição de competências e habilidades. Devem desenvolver o conhecimento da área específica e da área pedagógica, bem como a transposição didática. (INSTITUTO FEDERAL DO TRIÂNGULO MINEIRO, 2013, p. 33-34, grifos nossos).

A efetividade apontada na avaliação do MEC, acerca da PPCC no âmbito do curso, e o contato inicial com o PPC (INSTITUTO FEDERAL DO TRIÂNGULO MINEIRO, 2013) impeliram este estudo, que visou analisar modos de funcionamento da Prática Pedagógica Componente Curricular (PPCC) do curso de Licenciatura em Ciências Biológicas do IFTM e suas contribuições na formação docente. Nessa perspectiva, buscou-se: (1) identificar as concepções, acerca da PPCC, de formadores e licenciandos, principalmente no que concerne ao seu papel na formação docente; (2) averiguar como eram mobilizadas: a noção de interdisciplinaridade, a articulação entre a área específica e a área pedagógica, bem como a transposição didática; e, (3) discutir os conhecimentos constituídos e/ou mobilizados nessa dimensão formativa.

Para compreender e situar a PPCC do IFTM foi pertinente analisar como esta dimensão formativa vem sendo estruturada nos cursos de Licenciatura em Ciências Biológicas ofertados pelos IF que compõem a Rede Federal de Educação Profissional, Científica e Tecnológica do país. Foi realizado um levantamento no e-MEC (Sistema de Regulação do Ensino Superior) em dezembro de 2016, e verificou-se que havia cadastrados 62 cursos de Licenciatura em Ciências Biológicas, iniciados e em atividade, ofertados por 28 IF distribuídos em 21 Estados. Em pesquisa desenvolvida nos sítios eletrônicos dessas instituições, foram encontrados 50 PPC disponíveis para consulta, cujas ementas foram analisadas para compreender os modos de funcionamento da PCC nesses cursos. Ainda foi feita uma pesquisa no Banco de Teses e Dissertações da Coordenação de Aperfeiçoamento de Pessoal de Nível Superior (Capes) e na Biblioteca Digital Brasileira de Teses e Dissertações (BDTD) com o intuito de verificar os trabalhos realizados sobre a PCC em cursos de Licenciatura em Ciências Biológicas dos IF. Para as buscas realizadas nessas bases de dados, foram utilizados os descritores: prática como componente curricular, licenciatura em Ciências Biológicas, e definiu-se o espaçotemporal entre os anos 2008 (ano de criação dos IF) e 2016 (ano da pesquisa in loco no IFTM). Foram encontrados 227 trabalhos no banco da Capes e 23 na BDTD. Desse total, apenas quatro dissertações e uma tese se referem direta ou indiretamente à temática da PCC. Acredita-se que a carência de pesquisas, acerca da estruturação da PCC nos cursos de Licenciatura em Ciências Biológicas ofertados pelos IF, pode ser explicada pelo fato da recente criação dessas instituições.

Para o desenvolvimento do estudo no curso de Licenciatura em Ciências Biológicas do IFTM, foi realizada pesquisa de abordagem qualitativa que utilizou diferentes metodologias e instrumentos de coleta de coleta de dados como: (1) acompanhamento, por meio da observação participante, das aulas das disciplinas do $8^{\circ}$ período que tinham carga horária de PPCC, a saber: Biogeografia; Educação Ambiental; Geologia e Paleontologia e Prática Pedagógica VIII; (2) realização de oito encontros gravados, em áudio e vídeo, com os estudantes e professores para reflexão acerca da PPCC, elaboração e divulgação de material didático; (3) análise do 
PPC (INSTITUTO FEDERAL DO TRIÂNGULO MINEIRO, 2013), dos planos de ensino das unidades curriculares que tinham carga horária de PPCC, dos projetos e relatórios, elaborados pelos docentes, acerca dessa dimensão formativa. Foi também realizada a análise do perfil acadêmico e profissional dos formadores do curso, mediante consulta a seus currículos na Plataforma Lattes.

A opção pelo $8^{\circ}$ período se deu uma vez que os licenciados estavam em fase de finalização do curso e, dessa forma, poderiam contribuir oferecendo um maior aporte de experiências e vivências pregressas com a PPCC. Participaram da pesquisa 19 licenciandos e três professores formadores que ministravam as referidas disciplinas. Para preservar as identidades dos participantes, eles foram nomeados, aqui, da seguinte forma: os formadores, de professor A, B e C e os licenciandos foram numerados de forma aleatória, cuja numeração precede o número da turma, a 4.

A consulta ao PPC de Licenciatura em Ciências Biológicas do IFTM e às propostas e aos relatórios, elaborados pelos docentes, acerca dessa dimensão formativa, e as observações participantes iniciais nas aulas das disciplinas que tinham carga horária de PPCC do $8^{\circ}$ período do curso demonstraram que, embora estivesse prevista no currículo, as produções dos licenciandos não eram embasadas em uma integração de diferentes disciplinas. Foi nessa perspectiva que a pesquisadora propôs ao docente de Prática Pedagógica VIII, e depois em reunião com os demais docentes das unidades curriculares com carga horária de PPCC do $8^{\circ}$ período, a elaboração de um livro (igual ou superior a 50 páginas) ou livreto (inferior a 50 páginas) sobre a temática Aedes aegypti, que apresenta interfaces com as unidades curriculares de Biogeografia, Educação Ambiental e Geologia e Paleontologia. Os licenciandos elaboraram, durante o 8. ${ }^{\circ}$ período do curso de Licenciatura em Ciências Biológicas do IFTM, sob a supervisão dos formadores e da pesquisadora, o livro ITO: você me conhece? (SILVA; GUIDO, 2017)5. A proposta desse material se baseou no fato de esse suporte possibilitar o uso de vários recursos, como a pesquisa científica, a linguagem, a imagética, a dinâmica de colaboração, enfim, elaborar esse material, junto ao grupo, poderia contribuir para que os licenciandos utilizassem a criatividade e os conhecimentos aprendidos para a produção de um material diferente dos que haviam elaborado ao longo da graduação.

Os dados da pesquisa foram analisados por meio da técnica da Análise de Conteúdo ( $A C)$, da qual foi eleita a categorização (análise temática) não quantitativa de Bardin (2011), com a utilização das três etapas: (a) pré-análise: contato inicial com os dados, observando os itens exaustividade, representatividade, homogeneidade e pertinência; (b) exploração do material: exploração dos dados e construção de indicadores e categorias; (c) tratamento dos dados, inferência e interpretação: elaboração do texto-síntese mediante a análise crítica e reflexiva dos resultados com o estabelecimento de conexões com o referencial teórico que subsidia o estudo. Do

\footnotetext{
${ }^{5}$ O livro foi lançado em 25 de outubro de 2017 durante a IV Semana Acadêmica da Biologia, que aconteceu durante a 14a Semana Nacional de Ciência e Tecnologia (SNCT). Quinhentos exemplares foram disponibilizados para distribuição gratuita, com o consentimento dos autores da obra, para todos os presentes, assim como para o Laboratório de Ensino de Ciências e Biologia do IFTM, campus Uberaba, Laboratório de Prática de Ensino do Instituto de Biologia da UFU, bibliotecas dos nove campi do IFTM, bibliotecas municipais das cidades de Uberaba e Uberlândia, biblioteca da UFU, campus Santa Mônica, escolas públicas municipais da cidade de Uberaba e escolas públicas estaduais da área de abrangência da Superintendência Regional de Ensino de Uberaba, todos no estado de Minas Gerais.
} 
exame dos dados emergiram duas categorias analíticas, sendo a primeira composta por três subcategorias, que serão discutidas.

\section{A Prática Pedagógica como Componente Curricular no Campo de Recontextualização Pedagógica e no Contexto de Reprodução}

Nesta seção são apresentadas as três subcategorias que compõem esta primeira categoria analítica e que servem de subsídios para o entendimento da segunda categoria.

\section{Concepções de Prática Pedagógica como Componente Curricular e seu Papel na Formação Inicial}

No PPC (INSTITUTO FEDERAL DO TRIÂNGULO MINEIRO, 2013) havia uma tentativa de estruturação curricular em consonância com o DPO, todavia, nem todas as unidades curriculares tinham carga horária de PPCC, indo de encontro com o disposto sobre essa dimensão formativa na Resolução CNE/CP n. ${ }^{\circ}$ 01/2002: "[...] não apenas nas disciplinas pedagógicas, todas terão a sua dimensão prática" (BRASIL, 2002, p. 5). Havia ainda ausência da definição da PPCC nos 19 planos de ensino nas unidades curriculares da formação específica e de Prática Pedagógica "[...] oferecendo condições de produção de diferentes sentidos a respeito da PPCC, fugindo da educacional", conforme defendido por Barbosa (2015, p. 88). O PPC traz as vozes dos seus autores, contendo o discurso que se propõe a exercer no curso, recontextualizado do Discurso Pedagógico Oficial (DPO) e também composto pelos entendimentos, vivências e experiências daqueles que participaram de sua elaboração, assim como pelo próprio discurso da instituição. Nessa perspectiva, corrobora-se com Viana e Coutinho (2017), que observaram como, por onde e com quais entidades a PCC age no currículo do Curso de Licenciatura em Ciências Biológicas da Universidade Federal de São João Del Rei (UFSJ). Os autores observaram que ela age no curso, promovendo uma necessidade de adequação de disciplinas, da relação universidade-escola e ainda como um elemento organizador e estruturador do currículo, estando presente em nove unidades curriculares pedagógicas. Em suas palavras: "[...] observar como, por onde e com quais entidades, a PCC age em um curso de licenciatura, é ter algumas percepções sobre como conceitos, sentidos e significados de prática de sua perfomance nesses currículos acadêmicos e na formação desses professores" (VIANA; COUTINHO, 2017, p. 259, grifos dos autores). Ainda na visão dos pesquisadores sobre a operacionalização de elementos da formação profissional, como a PCC, há necessidade de maior investimento, pesquisas e atenção.

Segundo Terreri e Ferreira (2013, p. 1003, grifos das autoras), as DCN “[...] defendem a dimensão prática como um princípio organizador dos currículos que deve estar presente ao longo de todo o curso". Essa compreensão de que a dimensão prática dos cursos de licenciatura deve ser configurada em tempos e espaços determinados, contribui para que à PCC, que deve ter no mínimo 400 horas, seja conferido um caráter disciplinar, ou seja, que seja organizada na forma de disciplinas. Essa estruturação é verificada na maioria (75\%) dos PPC dos cursos de Licenciatura em Ciências Biológicas dos IF que possibilitaram a análise da distribuição da carga horária de PCC nas matrizes curriculares. 
Diferentes sentidos conferidos à PPCC foram identificados no âmbito do curso de Licenciatura em Ciências Biológica do IFTM, lócus dessa pesquisa. Todavia, destaca-se o sentido denominado "instrumentalização técnica", terminologia usada por Pimenta e Lima (2006) quando discutem a problemática do "reducionismo dos estágios às perspectivas da prática instrumental e do criticismo".

Em relação à configuração da PPCC do curso de Licenciatura em Ciências Biológicas do IFTM, o relevo atribuído à PPCC nas 19 unidades curriculares em que havia focalização na elaboração dos materiais didáticos para o ensino de conteúdos específicos selecionados, esmaecia a disciplina de Prática Pedagógica, ressaltando uma formação consoante ao modelo da racionalidade técnica. A PPCC era concebida enquanto ensaio à docência e como instrumentalização de recursos didáticos, aplicados nos momentos de estágio e durante atividades no Programa Institucional de Bolsa de Iniciação à Docência (PIBID), conforme depreendido das falas a seguir 6 :

\begin{abstract}
Professor B: [...] Na verdade, o que eu vejo muito são as atividades, tanto de estágio, mas também PIBID, serem alimentadas, pelo menos parcialmente, com as atividades realizadas no PPCC. Então o PPCC, em sala de aula, com as diferentes unidades curriculares, são desenvolvidas algumas atividades que permite um ensino dessas unidades curriculares enquanto vocês vão, os alunos vão pra sala de aula e com o PIBID ou um estágio, eles estão municiados, pelo menos parcialmente, com o PPCC para darem as aulas. [...]

Estudante 0415: Primeiros PPCCs a gente tinha muita questão de jogo, modelo, né? Tanto que a gente trabalhou muito com jogo, com modelos, só que aí chegou um momento que eu comecei a pensar: 'nossa, mas onde que a gente vai usar?' Aí entra a questão do PIBID. A gente levava o material pro PIBID e lá ajudava, auxiliava, criava mais modelos ou reproduzia aqueles que já tinha. [...]. Fazer para pôr em prática, porque a gente pensava em cumprir aquilo. Aí tem que fazer, então vamos fazer.
\end{abstract}

Depreende-se das falas, que há uma concepção utilitarista acerca da PPCC, compreendendo-a enquanto uma atividade prática, demarcando espaços para a teoria e a prática, voltada à produção de material didático. Nesse sentido, Silvério (2014, p. 61) defende que:

[...] para que a PCC possa se constituir a partir de experiências significativas de integração teoria-prática na formação, ela precisa ser concebida a partir de uma organização curricular que ajude a superar a visão aplicacionista da teoria e a visão ativista da prática.

Ainda, é possível depreender das falas que, para que seja conferido sentido à PPCC, é necessária a articulação das atividades realizadas nessa dimensão formativa com o ambiente escolar, indo ao encontro com o que as DCNs estabelecem acerca da necessidade de aproximação entre a instituição formadora e a escola mediante a investigação e reflexão crítica da prática docente. Todavia, a compreensão de que o contexto escolar é um lugar de aplicação da teoria, um campo de experimentação da prática, ratifica a dicotomia teoria e prática, colocando o contexto escolar enquanto lócus de reprodução de conhecimentos. Nessa perspectiva, corrobora-se com Viana et al. (2012, p. 43), que advertem que "[...] torna-se imperativo que os formadores

${ }^{6} \mathrm{As}$ falas foram transcritas exatamente como os participantes se manifestaram. 
de professores fiquem atentos a como se criam hierarquias entre as formas de conhecimento que colocam a escola, frequentemente, em posição inferior em relação à universidade".

\section{A Articulação entre a Área Específica e a Área Pedagógica}

O PPC destacava que, na disciplina de Prática Pedagógica, o professor responsável orientava a reflexão-ação-reflexão integrando as diversas áreas do conhecimento e que a prática docente se apresentava inserida formalmente, por meio da PPCC, em disciplinas selecionadas na forma de Projetos Integrados (INSTITUTO FEDERAL DO TRIÂNGULO MINEIRO, 2013). Todavia, no Contexto de Reprodução, cada professor das disciplinas com carga horária de PPCC, solicitava uma produção de material didático baseada no conteúdo que ministrava. No que se refere à articulação entre a área pedagógica e a área específica, havia um olhar dicotômico acerca da prática e da teoria, no qual a primeira deveria ficar restrita à disciplina de Prática Pedagógica, enquanto atividades práticas, e a segunda, nas demais 19 unidades curriculares com carga horária de PPCC. À Prática Pedagógica era conferida uma função de instrumentalização de conteúdos pedagógicos mais gerais, coexistindo com a área específica que definia o (re)contexto da PPCC.

Foi possível ainda depreender o que Oliveira (2016) verificou quando entrevistou docentes de alguns cursos de Licenciatura em Ciências Biológicas dos IF mineiros. A autora constatou, nos relatos dos formadores da área específica, que grande parte são licenciados e bacharéis, cujas formações, consoante o modelo 3+1 (GATTI, 2010), influenciam na concepção e elaboração dos PPC, favorecendo a área específica. Todavia, segundo Mohr e Cassiani (2017), que pesquisaram o Curso de Graduação em Ciências Biológicas da Universidade Federal de Santa Catarina (UFSC), os processos de concepção, proposta e execução da PCC cabe a quase todos os professores e disciplinas do curso.

Nessa perspectiva, é necessário que os formadores tenham a orientação apropriada do código pedagógico, que, segundo Morais e Neves (2005), está relacionado à aquisição das regras de reconhecimento e das regras de realização, terminologias estas que fazem parte do arcabouço conceitual bernsteniano acerca das relações empreendidas na prática pedagógica. As regras de reconhecimento permitem a identificação dos significados pertencentes a cada contexto e as regras de realização proporcionam meios para a escolha dos sentidos apropriados a um contexto e à produção do texto legítimo (SANTOS, 2003). Dessa forma, de acordo com Morais e Neves (2005), se o docente tem ambas as regras, significa que ele deve reconhecer o contexto e, também, produzir o texto adequado a esse contexto, ou seja, em suas práticas pedagógicas.

Os estudantes do curso de Licenciatura em Ciências Biológicas do IFTM conferiam maior relevância às outras unidades curriculares em detrimento da área pedagógica e havia ainda um entendimento diferenciado acerca do que era a PPCC na disciplina de Prática Pedagógica e do que era a PPCC nas demais 19 unidades curriculares, cujas atividades práticas pareciam estar desvinculadas do conteúdo pedagógico, conforme se depreende da fala do estudante 0407. 
Estudante 0407: A Prática Pedagógica é de grande importância para direcionar no ensinoaprendizagem, assim como o PPCC são instrumentos fundamentais para o desenvolvimento na prática, pois quando o conteúdo é visualizado com algo didático na sala de aula despertará o interesse do aluno. [...].

Havia maior dedicação ao conhecimento biológico, representando a hierarquização existente entre os conteúdos de formação, a qual era legitimada pela ampla carga horária de conteúdo de áreas específicas das Ciências Biológicas. O corpo docente efetivo, composto em sua maioria por professores com titulações em áreas específicas das Ciências Biológicas, legitima essa conformação do discurso pedagógico exercido no âmbito do curso.

Para esse âmbito da discussão, recorre-se às conceitualizações elaboradas por Bernstein (1999) acerca dos diferentes tipos de discurso, as quais denomina "discurso horizontal" e "discurso vertical", que podem ser consideradas diferentes formas de conhecimento, complementares, e não contrárias. O autor define que o discurso horizontal é o conhecimento do cotidiano ou conhecimento do senso comum. Por sua vez, o discurso vertical tem duas formas. Uma delas "[...] assume a forma de uma estrutura coerente, explícita, e sistematicamente baseada em princípios, organizada hierarquicamente como nas ciências [...]" (BERNSTEIN, 1999, p. 159, tradução nossa), a qual denomina "estruturas hierárquicas de conhecimento". A outra, intitulada "estruturas horizontais de conhecimento", apresenta-se como "[...] uma série de linguagens especializadas com modos especializados de interrogação e critérios especializados para produção e circulação de textos, como nas ciências sociais e nas humanidades" (BERNSTEIN, 1999, p. 159, tradução nossa). Explica que essas últimas podem variar entre aquelas com uma gramática forte e aquelas com uma gramática fraca. As estruturas horizontais de conhecimento marcadas por gramáticas fortes apresentam "[...] uma sintaxe conceitual explícita, capaz de descrições empíricas 'relativamente' precisas e/ou de geração de modelagem formal de relações empíricas" (BERNSTEIN, 1999, p. 164, grifo do autor, tradução nossa). O mesmo autor cita como exemplo a Economia, a Linguística, alguns campos da Psicologia e a Matemática e, por sua vez, com menos linguagens internas, considera, como exemplo de estruturas horizontais de conhecimento assinaladas por gramáticas fracas, a Sociologia, a Antropologia Social e os Estudos Culturais.

Morais e Neves (2012), fundamentadas em Bernstein (1999), ao tomarem a Biologia como exemplo de conhecimento de estrutura hierárquica, afirmam que o desenvolvimento de uma linguagem conceitual em Biologia, como em qualquer conhecimento de estrutura hierárquica, corresponde ao desenvolvimento de teorias continuamente mais gerais e integradoras. Por sua vez, no caso das estruturas horizontais de conhecimento, como a Sociologia, o que conta é, segundo Bernstein (1999), a introdução de uma nova linguagem, possibilitando nova perspectiva, novas questões e conexões, aparentes novas problemáticas e novos teóricos. Nesse sentido, Morais e Neves (2012, p. 67, grifo das autoras) explicam que:

Os professores e educadores de ciências, que são primariamente socializados dentro de estruturas hierárquicas específicas de conhecimento, encontram frequentemente dificuldade em aceitar conhecimentos caracterizados por linguagens paralelas. Aquela socialização primária prepara os professores e educadores de ciências para o que do ensino e da aprendizagem. Contudo, o como 
do ensino e da aprendizagem requer dos professores um processo posterior de socialização dentro de estruturas horizontais do conhecimento. Para conciliar estes dois processos de socialização, os professores têm de dar um "grande salto», especialmente quando passam de estruturas hierárquicas de conhecimento para estruturas horizontais de conhecimento caracterizadas por gramáticas fracas.

Dessa forma, compreende-se que esse processo demanda um movimento constante de esbatimento de fronteiras entre áreas do conhecimento, entre discursos e entre sujeitos, assim como demanda uma contínua reflexão por parte dos formadores de professores no que concerne à estruturação do currículo e às suas práticas pedagógicas.

\section{A Abordagem Interdisciplinar}

O PPC enfatizava que a PPCC deveria privilegiar a formação interdisciplinar (INSTITUTO FEDERAL DO TRIÂNGULO MINEIRO, 2013). Não obstante, no Contexto da Reprodução, havia a predefinição da natureza das produções realizadas, assim como a seleção dos conteúdos a serem trabalhados nas atividades de cada unidade curricular, o que parecia não contribuir para a formação interdisciplinar. Essa conformação do discurso pedagógico do curso vai de encontro ao disposto no Parecer CNE/CP n. 09/2001 que ressalta que a organização curricular deve permitir o constante aprofundamento de conhecimentos disciplinares, assim como promover a reflexão e a indagação acerca da relevância e pertinência desses conhecimentos "[...] para compreender, planejar, executar, avaliar situações de ensino e aprendizagem. Essa indagação só pode ser feita de uma perspectiva interdisciplinar" (BRASIL, 2001, p. 54). A focalização em conteúdos isolados confere um estatuto diferenciado a determinados conteúdos. Essa estruturação evidencia que cada docente, no seu campo de atuação, tem uma maior autonomia na seleção dos conteúdos e no modo de ensiná-los, conformação essa que leva ao isolamento e ao fortalecimento das fronteiras entre as diferentes áreas do conhecimento ou mesmo entre os professores (BERNSTEIN, 1996; DOMINGOS et al., 1986). Acerca da noção de interdisciplinaridade, as concepções dos professores se convergiam com relação à concepção unitária do conhecimento.

Professor B: [...] A interdisciplinaridade ela aflora fácil, não quer dizer que é simples. Tem que conversar muito, trabalhar bastante, pra chegar num produto bom. Nenhum tema é estanque numa única disciplina.

Professor A: Oconteúdo éum só, tudo existejunto, ao mesmo tempo [...]. Então, a interdisciplinaridade é uma tentativa de aproximar a gente da realidade porque as coisas acontecem juntas, ao mesmo tempo, tá tudo ligado. [...].

Todavia, para o desenvolvimento de um empreendimento interdisciplinar, é fundamental o envolvimento entre as diferentes disciplinas ou áreas do conhecimento, assim como depende das turmas de licenciados, conforme evidenciado na fala do professor B:

Professor B: [...] eu já fiz PPCC de diversos moldes, tem algumas que eu costumo dar com mais frequência, mas já tinha dado PPCC interdisciplinar, e isso sempre depende das turmas e dos professores que estão envolvidos nos PPCCs. E sempre em algum momento surge alguma ideia diferente, sempre não, sempre que surge e ela é viável, a gente acaba implantando [...] 
Ao contrário dessa perspectiva, compreende-se que a interdisciplinaridade pode também ser realizada por um único sujeito, uma vez que, nas palavras de Jantsch e Bianchetti (2011, p. 25): "[...] à ideia de que somente é possível ser interdisciplinar em grupo, contrapomos a de que a sós também é possível. Um grupo pode ser mais homogêneo e superficial que o indivíduo que busca recursos de várias ciências para explicar determinado processo". Todavia, segundo Japiassú (1975), faz-se necessário, nos empreendimentos interdisciplinares, não negligenciar as especialidades das diferentes disciplinas. No que se refere ao curso do IFTM, os estudantes, na elaboração do livro ITO: você me conhece?, mediante a preocupação de demarcação dos conteúdos de Biogeografia, Educação Ambiental e Geologia e Paleontologia dentro da história, apresentavam uma concepção que cursa, segundo Dellatre (2006, p. 280), com a pluridisciplinaridade, a qual é toda construção teórica que coloca em prática diferentes saberes por meio de "[...] uma simples associação de disciplinas que concorrem para uma realização comum, mas sem que cada disciplina tenha que modificar significativamente a sua própria visão das coisas e dos próprios métodos".

Estudante 0411: E foi uma dificuldade absurda pra encaixar a Educação Ambiental Crítica nessa temática. Aí não lembro quem falou: não, vamos fazer isso, isso e isso, e acabou que no final deu certo. [...]

Estudante 0407: As informações foram bem encaixadas no Livro. Confesso que fiquei muito a pensar no início: Como iríamos fazer essa sintonia de várias matérias, mas no final deu certo.

Observa-se ainda, nas proposições, ênfase às partes isoladas, em um primeiro momento, quando focalizavam em encaixar os conteúdos das disciplinas de Biogeografia, Educação Ambiental e Geologia e Paleontologia, com a finalidade de buscar por uma unidade fundamental, o todo. E, em um segundo momento, percebese uma visão holística, em que o todo, o Livro, tornava-se a parte mais relevante do sistema em detrimento das partes que o compõem. Essas duas perspectivas também foram observadas por Ruas e Araújo (2017), quando investigaram as concepções de interdisciplinaridade por meio de desenhos confeccionados por licenciandos em etapa inicial do curso de Ciências da Universidade Federal do Rio Grande (FURG) e professores de Ciências atuantes na rede básica das escolas municipais de ensino. Nas palavras de Ruas e Araújo (2017, p. 62), "[...] as duas perspectivas reduzem suas qualidades emergentes, simplificando o que há de complexo [...]".

A proposta de elaboração do livro ITO: você me conhece? visou estimular a interdisciplinaridade, uma vez que, segundo Fazenda (2011), a integração é uma fase necessária para a consecução da interdisciplinaridade, é uma etapa de organização e estudo dos conteúdos das disciplinas, uma etapa para a interação que ocorre somente "[...] num regime de coparticipação, reciprocidade, mutualidade (condições essenciais para a efetivação de um trabalho interdisciplinar)" (FAZENDA, 2011, p. 46). Todavia, a autora alerta que "[...] interdisciplinaridade não se ensina nem se aprende, apenas vive-se, exerce-se e, por isso, exige uma nova pedagogia, a da comunicação. [...] Assim sendo, pressupõe uma atitude engajada, um comprometimento pessoal" (FAZENDA, 2011, p. 11). Ou seja, o pensamento interdisciplinar pode ser estimulado, contudo, é volitivo e requer práticas fundamentadas em um discurso vertical assinalado por estruturas horizontais de conhecimento. Nesse sentido, torna-se importante refletir sobre a relevância de estimular práticas dialógicas, no contexto da PPCC, entre 
formadores e entre formadores e licenciados, uma vez que, segundo Fazenda (2011), a reciprocidade visa a um enriquecimento mútuo, possibilitando novas formas de enxergar e lidar com o conhecimento que podem contribuir para o despertar da denominada "atitude interdisciplinar".

\section{Conhecimentos Constituídos, Recontextualizados e/ou Mobilizados para o Ensino de Ciências e Biologia}

O PPC dispunha, com relação à PPCC, que "[...] os conteúdos deverão ser tratados como meio e suporte para a constituição de competências e habilidades" (INSTITUTO FEDERAL DO TRIÂNGULO MINEIRO, 2013, p. 34), indo ao encontro do disposto no DPO (BRASIL, 2002). Dias e Lopes (2003) questionam esse modelo de currículo para a formação de professores, desenvolvido especialmente nas universidades, que se baseia nas experiências acadêmicas. Consoante às autoras: "[...] a recontextualização do currículo da formação de professores baseada nas competências modifica o foco da aprendizagem escolar, na qual os conteúdos e as disciplinas passam a ter valor apenas como meios para constituição de competências" (DIAS; LOPES, 2003, p. 1172). Esse tipo de formação, segundo as autoras, tem sido basilar nas reformas curriculares visando à formação de um professor eficiente para atender às necessidades da sociedade, ou seja, "[...] um novo modelo de docente, mais facilmente controlado na produção de seu trabalho e intensificado nas diversas atividades que se apresentam para a escola e, especialmente, para o professor" (DIAS; LOPES, 2003, p. 1171).

No que se refere à PCC, segundo Vizzotto (2014, p. 15), "[...] se o conteúdo é meio e o fim é a competência, distancia-se do conceito de práxis". A autora explica que:

\footnotetext{
A PCC é parte constituinte do Trabalho Didático e sua 'aparição' nos documentos oficiais, com carga horária considerável, destaca-se num momento histórico em que o modelo de competências no meio educacional é largamente difundido. Este, por sua vez, tem como base o conceito de prática como fundamento da ação do professor, ou seja, a ação para resolver situações-problemas exige o desenvolvimento de determinadas habilidades e competências. Neste ciclo, formado por PPC, relação teoria/prática e competência, um sustenta o outro na medida em que a prática afirma-se à teoria e deste modo, se justifica e sobrepõe na PCC. (VIZZOTTO, 2014, p. 14, grifo do autor).
}

Para a efetivação da PPCC, é necessária a promoção de situações em que os conhecimentos sejam constantemente constituídos e/ou mobilizados. Contudo, corrobora-se com Vizzotto (2014, p. 14, grifos nossos) que defende: "[...] o que se deseja na realização do trabalho didático é uma ação intencional, mediada pela teoria e, para tanto, o conhecimento não é apenas o meio para alcançar o desejado".

Com relação à PPCC do curso de Licenciatura em Ciências e Biologia no IFTM, mediante as análises dos planos de ensino das unidades curriculares, verificou-se que a estruturação nas 19 unidades curriculares, com carga horária para essa dimensão formativa, proporcionava a constituição do conhecimento do conteúdo específico. Conquanto a disciplina de Prática Pedagógica no $7 .^{\circ}$ e $8 .^{\circ}$ períodos previsse atividades voltadas ao Ensino de Ciências e Biologia, a configuração da Prática Pedagógica, ao longo dos oito semestres do curso, proporcionava a constituição do conhecimento pedagógico para as situações de ensino e aprendizagem mais gerais. Havia também, 
nos planos de ensino de Prática Pedagógica, a previsão de observações de campo no ambiente escolar, contribuindo para a constituição do conhecimento do contexto. Todavia, acerca da constituição desse conhecimento, a sequência de diálogos dos estudantes evidencia um silêncio. As falas são relativas à área específica e sobre os materiais didáticos elaborados para cada unidade curricular e, no que se refere à constituição e/ou mobilização do conhecimento do contexto, apresentam convergências e divergências.

Estudante 0415: Aí, mas sempre houve a questão de ser só daquela disciplina e às vezes aquele modelo a gente não conseguiu utilizar lá no ensino básico. Dependendo da disciplina não dava pra usar lá no ensino básico.

Estudante 0402: É que a gente fazia o nível do conteúdo ali pra gente.

Estudante 0415: Pro ensino superior. Era muito técnico. Porque também não tinha vivência de sala de aula, então a gente não sabia o que dava certo.

Estudante 0402: Sem saber se a aplicação daria certo. É o que a gente via em sala de aula e aí a gente tinha que dar uma adaptada e aí que começou a proposta de fazer para o ensino médio e a gente aplicar na sala de aula com os alunos do PIBID.

Estudante 0411: [...] A gente tinha que apresentar aquilo no formato de aula, então não era só o material que era avaliado, era avaliado a gente também. A gente tem que saber o que que a gente está fazendo, igual [o 0416 falou], também a gente tem que pensar nos nossos alunos, na questão das inteligências múltiplas. [...]

Estudante 0401: PIBID, estágio e atuar diretamente como professor concordo com a fala [do 0415], são muito diferentes, ao tomar frente de uma sala de aula.

A proposição do estudante 0401 remete que o conhecimento do contexto só é realmente adquirido ou só faz sentido quando o licenciando se torna professor. Conquanto a dicotomia teoria e prática sejam depreendidas dos diálogos, ainda é possível inferir, da fala do estudante 0411, a constituição e/ou mobilização do conhecimento pedagógico do conteúdo que, segundo Shulman (1987, p. 8, tradução nossa): "[...] é aquele amálgama especial entre conteúdo e pedagogia que pertence exclusivamente aos professores". Nesse sentido, o conhecimento pedagógico do conteúdo, segundo Shulman (1986, 1987), significa ensinar um conteúdo mediante estratégias e técnicas necessárias para tal ensino, incorporando também as preconcepções que os estudantes trazem para as situações de aprendizagem. Com relação ao quê e como ensinar, ao longo da pesquisa evidenciou-se o que Bernstein (1996) define acerca da intervenção ideológica, que cria regras de ordem social cada vez que um discurso é deslocado de sua posição anterior para uma nova. Na sequência de diálogos, quando os estudantes realizavam a leitura das primeiras escritas do Livro, é possível verificar esse processo de recontextualização.

Estudante 0411: Então, nessa classificação eu coloquei uns asteriscos aqui na frente. Eu acho que como vai ser questão de ensino médio eles veem mais reino, filo, classe.

Estudante 0415: Ao meu ver, pro público ler, é o reino, filo, classe, ordem, gênero e espécie. No ensino médio, é isso que a gente vai falar. Aí eu acho que fica mais fácil deles reconhecerem.

Ao definirem quais categorias da classificação taxonômica do Aedes aegypti deveriam ser elencadas no Livro, depreende-se que, no processo de recontextualização, 
[...] os diferentes textos são simplificados, resumidos e reelaborados. Partes são aproveitadas, outras são desconsideradas, releituras são feitas e ideias inicialmente propostas são inseridas em contextos outros, que permitem sua ressignificação. (LOPES; MACEDO, 2011, p. 104).

Nesse processo de recontextualização do discurso pedagógico, segundo Morais e Neves (2012), pode-se incorrer ainda na diminuição do nível de exigência conceitual. De acordo com as autoras, para aumentar o nível de exigência conceitual, além da complexidade do conhecimento científico e das capacidades cognitivas envolvidas no processo de ensino-aprendizagem, as relações intradisciplinares devem apresentar uma classificação fraca entre os vários conteúdos de uma dada disciplina, ou seja, deve haver um esbatimento entre as fronteiras dos vários conteúdos da disciplina, uma vez que o conteúdo trabalhado pode se relacionar com os outros da mesma disciplina. Ainda, segundo as autoras, estudos desenvolvidos por pesquisadores do grupo ESSA sugerem, em geral, uma diminuição do nível de exigência conceitual no processo de recontextualização das orientações gerais para as orientações específicas do currículo e dessas para os livros escolares e práticas pedagógicas dos professores.

No que se refere ao processo de elaboração do livro ITO: você me conhece? foi possível depreender que os estudantes recontextualizaram a temática Aedes aegypti, segundo as concepções trabalhadas na unidade curricular Educação Ambiental. Todavia, apresentaram dificuldades de conjecturar conhecimentos científicos e sociais na busca de relações dos conteúdos com a problemática em torno do Aedes aegypti. Infere-se que essa situação ocorreu na elaboração do Livro, porque os estudantes se preocupavam com a demarcação dos conteúdos na história. Entretanto, durante a observação participante nas aulas das disciplinas do $8 .^{\circ}$ período, foi possível verificar que eles conseguiam trabalhar e recontextualizar as temáticas com maior facilidade quando a proposta era direcionada a uma intervenção específica, à solução de um problema em particular. Procuravam articular os conceitos próprios das Ciências Biológicas e suas relações com o cotidiano, uma vez que, durante as seleções realizadas por eles, buscavam conferir sentido ao que estavam ensinando. Introduziam exemplos de situações cotidianas e as explicavam com base no conhecimento escolar, proporcionando acesso aos contextos e, nesse processo, de acordo com Morais (2001, p. 14), introduz "[...] implicitamente, [...] os princípios que permitem distinguir esses mesmos contextos".

\section{Considerações Finais}

Há quase duas décadas a expressão prática como componente curricular passou a vigorar na redação dos textos oficiais que orientam a formação docente no país. Todavia, nos processos de recontextualização do DPO, o qual é demarcado por "continuidades e rupturas" (SCHNEIDER, 2007, p. 6), com fundamentação em um ensino pautado pela aquisição de competências e enseja relativa autonomia às instituições formadoras, a PCC, enquanto dimensão formativa, ainda causa estranhezas, incompreensões e subversões quando da sua organicidade e efetividade na formação de professores. Essa problemática demonstra que se leva tempo para que as reformas curriculares efetivamente ocorram, sendo elas constantemente balizadas pelos diferentes campos recontextualizadores que compõem o aparelho pedagógico 
oficial, evidenciando, segundo Terreri e Ferreira (2013, p. 1001), "recontextualizações, hibridismos e ambivalências".

Os IF contribuíam com a oferta de cerca de $10 \%$ dos cursos de Licenciatura em Ciências Biológicas do país, de acordo com a pesquisa realizada no e-MEC, em 2016. Dessa forma, ressalta-se a importância de se compreender a operacionalização da PCC nesses cursos, uma vez que essas instituições são originárias das antigas escolas técnicas, cuja ênfase se dava em uma formação para o atendimento aos cenários econômico e produtivo. Assinala-se que o ensino médio integrado ao técnico, ofertado nessas instituições, deve ser considerado um expressivo campo para o trabalho com a PCC. Faz-se necessário destacar que docentes que ministram Prática Pedagógica nos cursos de Licenciatura em Ciências Biológicas e em Química do IFTM campus Uberaba têm realizado, no que concerne à PPCC, atividades com os licenciandos no ensino médio integrado ao técnico ofertado pelo campus, as quais têm oportunizado experiências e vivências no processo de ensino e aprendizagem.

Verifica-se ainda que a problemática em torno da operacionalização efetiva da PCC se defronta com a formação dos docentes dos cursos de licenciatura em Ciências Biológicas. Nesse sentido, é necessário que, segundo Viana et al. (2012, p. 43), nos processos de construção das relações entre teoria e prática na formação docente, haja "[...] um aprofundamento em áreas do conhecimento que problematizam questões sobre os alunos, a escola e a atuação dos professores [...]". Isso significa a necessidade de um constante aprofundamento em áreas assinaladas por estruturas horizontais do conhecimento, como pesquisas voltadas à área da Educação e Ensino de Ciências e Biologia. Dessa forma, a articulação entre a área pedagógica e a área específica deve ser efetivamente consolidada, para que a primeira não fique restrita ao ensino de conhecimentos pedagógicos mais gerais e a segunda, à transposição didática não reflexiva dos conteúdos biológicos. Com relação à operacionalização da PCC, Vizzotto (2014) alerta para a necessidade de centrar esforços caso essa dimensão formativa seja orientada para produzir algo no âmbito do ensino e a educação não deve formar apenas para o trabalho, mas contribuir para processos de humanização, "[...] o que, consequentemente, leva ao entendimento de que a organização do trabalho didático problematize o atual modelo de desenvolvimento e não apenas o reproduza" (VIZZOTTO, 2014, p. 16).

Acerca da PPCC do curso de Licenciatura em Ciências Biológicas do IFTM, ressalta-se que o curso foi criado recentemente, no ano de 2010, e os agentes envolvidos estão continuamente reestruturando e reavaliando a organização curricular e as estratégias da prática educativa. Por fim, compreende-se que houve um avanço no que concerne à formação de professores, direcionado pelos textos oficiais, principalmente no que concerne à implementação da PCC nos currículos dos cursos de licenciatura, contribuindo para uma maior articulação entre as diferentes unidades curriculares da área específica e pedagógica. Todavia, reenfatiza-se a importância de se incentivar estudos sobre a temática em tela, buscando melhor entendimento sobre a organicidade da PCC nos cursos de Licenciatura em Ciências Biológicas, com vistas a compreender os processos de produção e recontextualização que assinalam o contexto da formação docente e corroboram com a constante revisão dos currículos. 


\section{Referências}

BARBOSA, A. T. Sentidos da prática como componente curricular na licenciatura em ciências biológicas. 2015. 174 f. Dissertação (Mestrado em Educação Cientifica e Tecnológica) Universidade Federal de Santa Catarina, Florianópolis, 2015.

BARDIN, L. Análise de conteúdo. São Paulo: Almedina Brasil, 2011.

BERNSTEIN, B. A estruturação do discurso pedagógico: classe, código e controle. Petrópolis: Vozes, 1996.

BERNSTEIN, B. Vertical and horizontal discourse: an essay. British Journal of Education, London, $v$. 20, n. 2, p. 157-173, 1999. DOI: https://doi.org/10.1080/01425699995380.

BRASIL. Lei no 11.892, de 29 de dezembro de 2008. Institui a rede federal de educação profissional, científica e tecnológica, cria os institutos federais de educação, ciência e tecnologia, e dá outras providências. Brasília: Presidência da República, 2008. Disponível em: https://www.planalto.gov. br/ccivil_03/_ato2007-2010/2008/lei/l11892.htm. Acesso em: 4 mar. 2021.

BRASIL. Parecer CNE/CP n 9/2001. Institui as diretrizes curriculares nacionais para a formação de professores da educação básica em nível superior. Diário Oficial da União: seção 1, Brasília, DF, p. 31, 18 jan. 2002.

BRASIL. Resolução CNE/CP no 1, de 18 de fevereiro de 2002. Institui diretrizes curriculares nacionais da educação básica, em nível superior, curso de licenciatura, de graduação plena. Diário Oficial da União: seção 1, Brasília, DF, p. 31, 9 abr. 2002.

BRITO, L. D. A configuração da prática como componente curricular nos cursos de licenciatura em ciências biológicas das universidades estaduais da Bahia. 2011. 154 f. Tese (Doutorado em Educação) - Universidade Federal de São Carlos, São Carlos, 2011.

DAVIES, B. Introduction. In: MORAIS, A. M.; NEVES, I.; DAVIES, H. (org). Towards a sociology of pedagogy: the contribution of Basil Bernstein to research. New York: Peter Lang, 2001.

DELATTRE, P. Investigações interdisciplinares: objetivos e dificuldades. In: POMBO, O.; GUIMARAES, H. M.; LEVY, T. Interdisciplinaridade: antologia. Porto: Campo das Letras, 2006. p. 279299.

DIAS, R. E.; LOPES, A. C. Competências na formação de professores no Brasil: o que (não) há de novo. Educação \& Sociedade, Campinas, v. 24, n. 85, p. 1155-1177, dez. 2003. DOI: https://doi. org/10.1590/S0101-73302003000400004.

DOMINGOS, A. M.; BARRADAS, H.; RAINHA, H.; NEVES, I. P. A teoria de Bernstein em sociologia da educação. Lisboa: Fundação Calouste Gulbenkian, 1986.

FAZENDA, I. C. A. Integração e interdisciplinaridade no ensino brasileiro: efetividade ou ideologia. São Paulo: Loyola, 2011.

GATTI, B. A. Formação de professores no Brasil: características e problemas. Educação \& Sociedade, Campinas, v. 31, n. 113, p. 1355-1379, 2010. DOI: https://doi.org/10.1590/S010173302010000400016.

INSTITUTO FEDERAL DO TRIÂNGULO MINEIRO. Resolução no 40/2013, de 27 de agosto de 2013. Aprovar a resolução ad referendum n 39/2013 que trata da revisão e atualização do projeto pedagógico do curso de licenciatura em ciências biológicas do Instituto Federal de Educação, Ciência e Tecnologia do Triângulo Mineiro: campus Uberaba. Uberaba: IFTM, 2013.

INSTITUTO FEDERAL DO TRIÂNGULO MINEIRO. Pró-Reitoria de Ensino. Relatório de avaliação: reconhecimento de curso licenciatura em ciências biológicas. Uberaba: IFTM, 2014. 
JANTSCH, A. P.; BIANCHETTI, L. A interdisciplinaridade: para além da filosofia do sujeito. 9. ed. Petrópolis: Vozes, 2011.

JAPIASSU, H. Interdisciplinaridade e patologia do saber. Rio de Janeiro: Imago, 1975.

KASSEBOEHMER, A. C.; FARIAS, S. A. Conteúdos das disciplinas de interface atribuídos a prática como componente curricular em cursos de licenciatura em química. Alexandria: revista de educação em ciência e tecnologia, Florianópolis, v. 5, n. 2, p. 95-123, 2012. Disponível em: https://periodicos.ufsc.br/index.php/alexandria/article/view/37716. Acesso em: 5 mar. 2021.

LIMA NETO, J. C. A prática como componente curricular na formação de professores de geografia. 127 f. 2018. Dissertação (Mestrado em Geografia) - Instituto de Estudos Socioambientais, Universidade Federal de Goiás, Goiânia, 2018.

LOPES, A. C.; MACEDO, E. Teorias de currículo. São Paulo: Cortez, 2011.

MOHR, A.; CASSIANE, S. Concepção, proposta e execução da prática como componente curricular no curso de graduação de ciências biológicas da Universidade Federal de Santa Catarina. In: MOHR, A.; WIELEWICKI, H. G (org.). Prática como componente curricular: que novidade é essa 15 anos depois? Florianópolis: UFSC, 2017. p. 61-86.

MOHR, A.; WIELEWICKI, H. G (org.). Prática como componente curricular: que novidade é essa 15 anos depois? Florianópolis: UFSC, 2017.

MORAIS, A. M. Práticas pedagógicas na formação inicial e práticas dos professores. Revista de Educação, Lisboa, v. 11, n. 1, p. 1-19, 2001.

MORAIS, A.; NEVES, I. P. Basil Bernstein: antologia. Revista de Educação, Lisboa, v. 10, n. 2, p. 149$159,2001$.

MORAIS, A.; NEVES, I. P. Os professores como criadores de contextos sociais para a aprendizagem científica: discussão de novas abordagens na formação de professores. Revista Portuguesa de Educação, Braga, v. 18, n. 2, p. 153-183, 2005. Disponível em: https://www.redalyc.org/articulo. oa? id=37418206. Acesso em: 5 mar. 2021.

MORAIS, A.; NEVES, I. P. A teoria de Basil Bernstein: alguns aspectos fundamentais. Revista Práxis Educativa, Ponta Grossa, v. 2, n. 2, p. 115-130, 2007. Disponível em: https://repositorio.ul.pt/ handle/10451/4390. Acesso em: 5 mar. 2021.

MORAIS, A.; NEVES, I. P. Textos e contextos educativos que promovem aprendizagem: optimização de um modelo de prática pedagógica. Revista Portuguesa de Educação, Braga, v. 1, n. 22, p. 5-28, 2009. Disponível em: https://www.redalyc.org/articulo.oa?id=37411987002. Acesso em: 5 mar. 2021.

MORAIS, A.; NEVES, I. P. Estruturas de conhecimento e exigência conceptual na educação em ciências. Educação, Sociedade \& Culturas, Lisboa, n. 37, p. 63-88, 2012.

OLIVEIRA, B. M. Licenciaturas em ciências biológicas nos institutos federais de educação, ciência e tecnologia de Minas Gerais e o ensino médio integrado. 2016. 173 f. Dissertação (Mestrado em Educação Tecnológica) - Centro Federal de Educação Tecnológica de Minas Gerais, Belo Horizonte, 2016.

OLIVEIRA NETO, J. F. Configurações da prática como componente curricular nos cursos de licenciatura em ciências biológicas de universidades públicas em Goiás: sentidos e implicações. 2016. 134 f. Dissertação (Mestrado em Educação em Ciências e Matemática) - Universidade Federal de Goiás, Goiânia, 2016.

PIMENTA, S. G.; LIMA, M. S. L. Estágio e docência: diferentes concepções. Poiésis, Florianópolis, v. 3, n. 3-4, p. 5-24, 2005/2006.

REAL, G. C. M. A prática como componente curricular: o que isso significa na prática? Educação e Fronteiras On-Line, Dourados, MS, v. 2, n. 5, p. 48-62, 2012. 
RUAS, F. P.; ARAÚJO, R. R. O todo e as partes como forma de expressão de Pontos de vista sobre interdisciplinaridade em ciências. Interdisciplinaridade, São Paulo, n. 11, p. 58-71, 2017.

SANTOS, L. L. C. P. Bernstein e o campo educacional: relevância, influências e incompreensões. Cadernos de Pesquisa, São Paulo, n. 120, p. 15-49, 2003.

SCHNEIDER, M. P. Diretrizes curriculares nacionais para a formação de professores da educação básica: das determinações legais às práticas institucionalizadas. 2007. 198 f. Tese (Doutorado em Educação) - Universidade Federal de Santa Catarina, Florianópolis, 2007.

SHULMAN, L. S. Those who understand: knowledge growth in teaching. Educational Researcher, Washington, v. 15, n. 2, p. 4-14, 1986.

SHULMAN, L. S. Knowledge and teaching: foundations of the new reform. Harvard Educational Review, Cambridge, Mass., v. 57, n. 1, p. 1-22, 1987.

SILVA, L. M. Itinerários da "prática como componente curricular": formação inicial de professores de ciências e biologia no instituto federal do Triângulo Mineiro - IFTM. 2019. 231 f. Tese (Doutorado em Educação) - Universidade Federal de Uberlândia, Uberlândia, 2019.

SILVA, L. M; GUIDO, L. E. (org.). ITO: você me conhece? Uberaba: IFTM, 2017. Disponível em: http://abre.ai/livroito. Acesso em: 4 mar. 2021.

SILVA, P.; MORAIS, A. M.; NEVES, I. P. O currículo de ciências no $1^{\circ}$ ciclo do ensino básico: estudo de (des)continuidades na mensagem pedagógica. Revista Portuguesa de Educação, Braga, v. 26, n. 1, p. 179-217, 2013.

SILVÉRIO, L. E. R. As práticas pedagógicas e os saberes da docência na formação acadêmicoprofissional em ciências biológicas. 2014. 485 f. Tese (Doutorado em Educação Científica e Tecnológica) - Universidade Federal de Santa Catarina, Florianópolis, 2014.

TERRERI, L.; FERREIRA, M. S. Políticas curriculares para a formação de professores: sentidos de teoria e prática nas ciências biológicas. Revista de Educação Pública, Cuiabá, v. 22, p. 999-1020, 2013.

VIANA, G. M.; COUTINHO, F. A. Prática como componente curricular: seguindo o conceito e analisando sua performance no currículo do curso de licenciatura em ciências biológicas da UFSJ. In: MOHR, A.; WIELEWICKI, H. G (org.). Prática como componente curricular: que novidade é essa 15 anos depois? Florianópolis: UFSC, 2017. p. 243-262.

VIANA, G. M.; MUNFORD, D.; FERREIRA, M. S.; MORO, L. Relações entre teoria e prática na formação de professores: investigando práticas sociais em disciplina acadêmica de um curso nas ciências biológicas. Educação em Revista, Belo Horizonte, v. 28, n. 4, p. 17-49, 2012.

VIZZOTTO, L. A Prática como componente curricular e a organização do trabalho didático na formação inicial de professores. In: ANPED SUL, 10., 2014, Florianópolis. Anais [...]. Florianópolis: Universidade do Estado de Santa Catarina, 2014.

ZABEL, M.; MALHEIROS, A. P. S. Prática como componente curricular: entendimentos, possibilidades e perspectivas. Educação Matemática Pesquisa, São Paulo, v. 20, n.1, p. 128-146, 2018. 